\title{
De santas a suspeitas e pecadoras
}

EUCLIDES MARCHI

Universidade Tuiuti do Paraná Universidade Federal do Paraná 


\section{Resumo}

Este artigo faz uma leitura de um dos principais documentos da Igreja católica do Brasil, publicado em 1915, e procura resgatar a imagem da mulher construída pela hierarquia católica. Tenciona captar algumas especificidades do discurso institucional, de modo especial o religioso, e mostrar que a busca da unidade discursiva era condição sine qua non para garantir o poder tanto dos enunciadores quanto da instituição.

\section{Palavras-chave}

discurso, instituição, poder

\section{Abstract}

This article is a reading of one of the main documents of Brazil Catholic Church, published in 1915. The study aims to recover the woman image created by the catholic hierarchy. It also intends to grasp some specificity from the institutional discourse, specially from the religious one. Finally it objectives to show that the search for a unique discursive language was a sine qua non condition to assure the power of the enunciators as well as of the institution.

\section{Key words}

discourse, institution, power 
A s pesquisas realizadas sobre a Igreja católica do Brasil permitiram vasculhar um importante conjunto de documentos institucionais e deles extrair, dentro do estudo da linguagem, algumas considerações do ponto de vista da análise do discurso. Este texto, especificamente, resulta da leitura das Constituições das provincias eclesiásticas meridionais do Brasil, documento subscrito por um cardeal e 26 bispos e publicado após as reuniões realizadas em 1915, na cidade de Nova Friburgo, no período de 12 a 17 de janeiro. As orientações nele contidas foram, posteriormente, adotadas também pelas Províncias Setentrionais, valendo, então, para toda a Igreja do Brasil. As normas nele contidas perduraram até o Concilio Vaticano II e algumas delas até os dias atuais.

O documento contém seis títulos - I. Fé; II. Sacramentos; III. Culto; IV. Disciplina do Clero; V. Costumes do Povo; VI. Promulgação das Constituições -, subdivididos em capítulos, que abarcam o conjunto de temas referentes ao funcionamento da instituição, à formação e procedimento dos seus membros, às questões de fé, doutrina e liturgia e outras questões relativas à vida e atuação da Igreja na sociedade. Trata-se, portanto, de um documento amplo, e seria temerário querer abordá-lo no seu todo num texto como este. Por isso, devido à sua dimensão, as considerações aqui alinhavadas recortam apenas um aspecto a partir do qual se busca fazer um exercício de análise do discurso institucional.

Antes de entrar no recorte documental, cabem algumas informações sobre a produção desse documento. Desde a separação entre a Igreja e o Estado no Brasil, decretada pelo governo republicano 
em 1890, a Igreja desenvolvia um trabalho de reorganização institucional, de unificação dos procedimentos discursivos e das práticas pastorais, litúrgicas e devocionais. Em sucessivas reuniões, o episcopado produzia as orientações e as publicava em Pastorais Coletivas e outros documentos com o intuito de buscar, efetivamente, uma (re)construção da Igreja como instituição religiosa, mesmo que isso possa parecer estranho e paradoxal após quatrocentos anos de vida e atuação na sociedade brasileira. Finalmente, em 1915, estava pronto o texto denominado Constituições das províncias eclesiásticas meridionais do Brasil, que definia a face da Igreja católica do Brasil, na condição de instituição livre num Estado livre.

Muitos historiadores já discutiram esse e outros documentos da época, porém, poucos se dedicaram a uma análise mais detalhada do ponto de vista discursivo, quer no todo, quer em parte. Além disso, este trabalho atém-se apenas a uma análise da linguagem verbal conforme nele expressa, abstendo-se de discutir os aspectos rituais ou as representações simbólicas produzidas pelas autoridades eclesiásticas no momento em que foram instados a criar uma nova imagem de Igreja.

A análise que aqui se realiza parte da concepção de que o discurso religioso é uma forma de linguagem que envolve, além dos fatores propriamente religiosos (como fé, crença e soteriologia), outros de ordem cultural e social presentes no contexto da vida cotidiana. As questões teóricas suscitadas pela análise de discurso, articuladas ao formato e ao conteúdo de um documento oficial (neste caso produzido por uma instituição religiosa), também contribuíram para uma reflexão sobre o tema das representações sociais, os mecanismos de controle de sujeitos históricos, bem como para compreender a organização institucional e a construção das estruturas de poder.

Do ponto de vista da análise do discurso, as leituras dos trabalhos de Michel Foucault, Dominique Maigueneau, Pierre Bourdieu, entre outros, em que pesem as divergências e as especificidades de seus posicionamentos teóricos, motivaram as reflexões sobre o texto analisado.

Significação $14 \cdot 240$ 
O tema recortado do texto das Constituições permitiu compor o tema central deste trabalho: a imagem da mulher construída pelo episcopado brasileiro no início do século XX. Um rastreamento detalhado do documento permitiu extrair apenas uma imagem de mulher produzida pelo olhar dos bispos: a santa e ao mesmo tempo a pecadora, perigosa e suspeita.

Para compor os aspectos dessa imagem, partiu-se das mulheres santas, isto é, aquelas dedicadas à vida religiosa; as mulheres que pertencem às congregações religiosas.

No dizer do episcopado, o mundo receberia de bom grado os Institutos de Caridade de mulheres, reconheceria neles a expressão perfeita do espírito da religião. A vida do claustro era apontada como a mais perfeita das que se poderiam seguir no seio da Igreja; as sagradas virgens eram consideradas as flores mais mimosas do seu jardim e a porção mais ilustre da grei de Cristo. O texto acrescenta: "Feliz o povo que tem um convento, em que floresça a observância regular! É um relicário do céu, flor da árvore eclesiástica, honra e formosura da graça e margarida preciosa da coroa do Redentor! É um para-raio, a desarmar o braço da ira de Deus" (IGReja Católica. BIsPos, 1915, $\mathrm{n}^{2} 1385$, p. 349).

Talvez essa seja a manifestação mais direta sobre a mulher santa, a mulher consagrada ao serviço da causa de Deus e da Igreja. Todavia, se o convento era motivo de felicidade para a sociedade ou para o povo, o discurso episcopal acrescenta um instigante outro lado da imagem, ou seja, um misterioso perigo rondava os conventos, especialmente a clausura! Com regras definidas desde Pio V em 1570, nela, além das freiras, ninguém mais poderia entrar sem a devida autorização, independentemente do sexo, idade, classe e condição social, e dela as freiras somente poderiam sair em caso de grande incêndio, lepra ou epidemia e com autorização, por escrito, do Ordinário. Até para ministrar os sacramentos a alguma freira enferma, o confessor somente entraria devidamente vestido de sobrepeliz e estola. O documento ainda ressalvava que, se esse confessor fosse do clero secular, deveria estar acompanhado de duas monjas, as chamadas escutas, e, se fosse do clero regular, um outro sacerdote 
de vida exemplar e de idade madura deveria acompanhá-lo. Todos os contatos com essas mulheres obedeciam a normas rigorosas e restritivas, e aqueles sacerdotes que falassem com as freiras após os sermões cometeriam penas graves.

Se nos conventos, especialmente na clausura, as mulheres que lá habitavam eram dignas de suspeita e suscitavam tanta preocupação ou, até, um declarado temor, perigo maior rondava os confessionários. O documento episcopal continha normas claras, explícitas e rigorosas sobre o funcionamento da confissão e todos os procedimentos a ela pertinentes. Considera-se importante lembrar que o texto trata de um dos sacramentos da Igreja, cuja prática, além de recomendada, era obrigatória. Mesmo assim, ao se tratar de mulheres no confessionário, a confissão, que era um sacramento, convertia-se em perigo para a penitente e para o confessor. Esta suspeita era oriunda não do tamanho do pecado, nem do perigo que poderia representar em termos de condenação eterna, mas da circunstância em que ocorria o encontro entre o padre e a mulher.

Assim, paradoxalmente, o confessionário, definido como o local destinado a obter o perdão dos pecados, aparece no documento episcopal como uma possibilidade de se transformar em ocasião de pecado. Nele, mulheres e sacerdotes poderiam estabelecer encontros reservados e perigosos. Por isso, as Constituições determinavam desde o local onde deveriam ser alocados os confessionários até seu projeto arquitetônico. Ou seja, deveriam ser visíveis a todos, sendo proibido colocá-los em locais escuros, nas sacristias ou nas casas dos confessores, e deveriam evitar maiores aproximações e impedir a ocorrência de sentimentos impertinentes e, sobretudo, impedir que o confessor e a penitente se vissem.

As preocupações e as determinações do episcopado não tinham como objetivo atingir o sacramento da confissão, mas o tipo de relacionamento que se poderia estabelecer entre a mulher e o padre no confessionário. Eis o que dizem os bispos: “(...) proibimos severamente aos confessores estabelecer e entreter longas conversações com mulheres no confessionário, quer pelo perigo que correm os mesmos confessores e suas penitentes, quer pelo escândalo 
que dão ao povo, quer pela perda de tempo, com prejuízo dos deveres sacerdotais" (I. C. BIsPos, 1915, n- 249\%, p. 63).

Até mesmo para confessar mulheres surdas há uma orientação expressa sobre o confessionário, isto é: “(...) poderão ser collocados em logares afastados, de modo a não serem ouvidas pelos circunstantes, mas à vista de todos" (I. C. BISPos, 1915, n² 291 I9, P-75).

Enquanto os homens poderiam ser atendidos em qualquer hora e lugar, as mulheres somente se confessariam na Igreja e à vista de outras pessoas. A esse respeito o documento é enfático: "Proibimos, pois, severamente que se confessem mulheres fora da Igreja e das grades do confessionário, nos corredores, sacristias, tribunais e coro" (I. C. BIspos, 1915, $\mathrm{n}^{2} 292-2^{2}$, p. 75). E, se houvesse necessidade de confessar alguém em lugares distantes de qualquer Igreja, poderse-ia fazê-lo em casas particulares, com as portas abertas e à vista de muitas pessoas, mas deveria haver sempre uma grade ou algo semelhante que separasse o confessor e a penitente. Até os confessionários das igrejas dos conventos deveriam permitir total visibilidade, sendo proibida sua localização nas sacristias, nas capelas internas ou em qualquer outro ponto que os deixassem ocultos. Os bispos esmeravam-se nos cuidados, por isso proibiam os padres de ouvir confissão de mulheres antes da aurora e depois do ocaso do sol.

Mas se a confissão, dadas as circunstâncias em que acontece e o clima emocional que a envolve, contribui para construir uma imagem de mulher duplamente pecadora, causa ainda maior surpresa ao verse expressa, no documento, a possibilidade de o altar, na hora da missa, também ser visto como ocasião de pecado e, por isso, impediase o trânsito de mulheres. As mulheres estavam expressamente proibidas de ocupar o lugar de acólito nas celebrações. Em caso de urgente necessidade, poderiam até responder à missa, porém fora do presbitério e em lugar separado do altar, tendo o sacerdote de preparar tudo de antemão para não precisar de seu ministério no altar (I. C. BIspos, 1915, n² 539, p. 149).

Instigante também é a maneira como o texto das Constituições coloca sob suspeição e, portanto, como ocasião de pecado qualquer 
outra possibilidade de contato ou relacionamento entre o sacerdote e sexo feminino. Assim, era rigorosamente proibido aos sacerdotes coabitar com pessoas de outro sexo, até mesmo com parentes próximos se fossem de pouca idade. Nenhum sacerdote deveria ir à casa dos fiéis quando estivessem ausentes os homens e lá somente se encontrassem as mulheres, principalmente se fossem jovens. Estava literalmente determinado: "A freqüência do sacerdote a casas onde há moças causa dano ao bom nome dele e delas" E como resolver o problemas das criadas necessárias aos serviços domésticos, nas igrejas e casas paroquiais? Elas deveriam ter pelo menos 40 anos de idade e satisfazer a outras condições exigidas pelos cânones (estas exigências estão omissas nas Constituições. Todavia supõe-se que fossem do conhecimento do clero). Além disso, caberia ao sacerdote vigiar para que sua casa não fosse freqüentada por mulheres a pretexto de amizade com as que lá residissem, porque, se estas não eram suspeitas, as outras poderiam dar motivos para isto. A lei determinava que, ao tratar com pessoas de outro sexo, era necessário usar de muita prudência e seriedade (I. C. BISPOS, 1915, ne 1343, p. 334).

As proibições sobre o relacionamento eram detalhadas a ponto de destacarem: "Não se assentem à mesa com suas criadas, nem entrem sem necessidade nos seus dormitorios nem nas salas ou quartos em que se applicam aos trabalhos domésticos" (1. C. Bispos, 1915, n² 1344, p. 334). E ainda:

Proibimos igualmente aos Revds. Sacerdotes que levem consigo em viagem de necessidade ou de recreio, por logares desconhecidos, quaesquer mulheres ainda que sejam parentes próximas de pessôas devotas e acima da menor suspeita, porque servirão de escândalo aos fieis por onde passarem e darão motivo para que murmurem da honra e dignidade de todo o clero(I. C.

Bispos, $1915, n^{\circ} 1345$, p. 335).

Qualquer intimidade era suspeita, pois, embora parentes, as mulheres não deveriam entrar, sem verdadeira necessidade, nos 
aposentos e salas em que se tratassem os negócios concernentes ao sagrado ministério ou onde se guardassem os livros, apontamentos ou escritos que a eles se referissem. Citam o texto do Concilio Plenário Latino Americano de 1899, que diz: “(...) Actum est de auctoritarte parochi, quem fideles a mulieris imperiosa voluntate pendere autumant" (CPLA, 1899, n 646 p. 282- "está perdida a autoridade do Párocho quando os fiéis creem que ele depende dos caprichos de uma mulher").

A preocupação com o convívio ou contato entre mulheres e padres, motivo de suspeita, ultrapassou os encontros fortuitos ou contatos casuais. Chegou até ao trabalho profissional. Assim, as Constituições também proibiam os sacerdotes de ensinar música e canto, ler e escrever, contar e outra qualquer matéria a meninas e mulheres de qualquer condição, sem antes obter licença do bispo, por escrito.

Desta forma, o episcopado, ao escrever as Constituições, revelava, por um lado, todo o seu zelo em relação ao princípio e à norma da castidade sacerdotal e, por outro, contínua suspeição sobre mulheres e sacerdotes. No documento, a castidade aparece assim retratada:

Velem os Sacerdotes com todo o cuidado para conservar immaculada a santa castidade que é o ornamento angélico e proprio da ordem sacerdotal, e evitem com toda a cautela tudo aquilo que possa trazer o mais remoto perigo para a celeste virtude ou a mais leve suspeita contra sua perfeição. Usem sempre de maxima prudência e reserva no tratar com pessôas de outro sexo, ainda as mais recommendaveis pela modéstia e piedade, nem as visitem com frequencia.

Nunca falem a sos com essas pessôas, nem as recebam em casa sem testemunhas, embora venham consultar sobre negocios espirituaes e reservados de sua consciência. Destes tratem na egreja e no confessionário, nas horas que houver frequencia de fieis, e nunca com as portas fechadas (I. C. BISPOS,

1915 , n. 1339, p. 333). 
Por isso, recomendavam ao clero que, ao tratar com pessoas de outro sexo, deveriam, além de usar de muita prudência e seriedade, evitar nutrir relações com pessoas de pouca reputação e conduta duvidosa. Nesse sentido, curiosa é a recomendação que os bispos fazem ao clero estrangeiro:

Habitem, quanto possivel, tres na mesma casa. Evitem morar em casas duvidosas ou onde sejam obrigados a levar vida promiscua com mulheres, expondo-se ao perigo de faltar à castidade ou de perde-la, que é gemma pretiosissima a paucis inventa, no dizer de São Thomaz; ou virtude que mundans mentes hominum, praestat videre Deum, como diz Santo Agostinho (I. C. Bıspos, 1915, 137. $5^{\circ}$ p. 34-35).

Até mesmo ao tratar do sacramento do matrimônio, a figura da mulher mereceu um destaque especial, sobretudo quando no que se refere às petições de dispensa de impedimentos existentes entre os contraentes. Aqui, os bispos valem-se da Instrucção da Sagrada Congregação De Propaganda Fide, de 9 de maio de 1877 Os casos que servem de exemplos para as dispensas retratam, majoritariamente, a situação das mulheres.

Assim, nas questões de parentesco, o documento destaca as situações nas quais a Igreja sempre buscará atender a condição da mulher e não a do homem:

- se a consangüinidade for tão propagada que se torne impossível à mulher casar com alguém que não seja parente, a menos que mude de lugar;

- se a mulher já tiver ultrapassado os 24 anos de idade, exceto as viúvas;

- se não tiver dote suficiente que possa se casar com estranho;

- se herdar um grande dote e por isso for muito cobiçada e tiver muitos pretendentes cujos objetivos sejam apenas os bens materiais; 
- se for viúva com muita prole e o esposo prometer sustentá-la;

- se a viúva for muito moça e viver em perigo de incontinência;

- se a mulher teve relações sexuais com parente e delas tiver filho, atendendo-se assim à honra da prole e da mulher, pois em caso de negação acabaria ficando solteira;

- nos casos em que a mulher tenha se relacionado com parente por causa da extrema familiaridade entre eles e se não casar acabará ficando difamada ou solteira.

Finalmente, até o ato de ensinar o catecismo poderia tornar-se uma situação suspeita, de tal sorte que os bispos orientam assim os seus párocos: "Durante o ensino procurem os Revds. Parochos que haja inteira separação entre meninos e meninas; e si fôr possivel, ensinem em logares ou horas diversas" (I. C. BIsPos, 1915, n9 40, p. 10).

Para se compreender a imagem da mulher retratada no texto das Constituições, é preciso estabelecer alguns parâmetros definidos pelo discurso institucional, especialmente o católico. Sua compreensão implica em algumas considerações preliminares mais amplas: o documento, ao referir-se à mulher, constrói uma imagem que traz embutida uma concepção de sociedade. Nela não somente prevalece uma divisão entre homens e mulheres, mas entre bons e maus, entre santidade e pecado. No relacionamento entre o homem e a mulher, esta constitui um mundo marcado pela imagem das "Evas" as pecadoras, as sedutoras. As "Marias" merecem poucas referências e, quando as fazem, são insuficientes para superar a condição de suspeitas.

Nessa visão dicotômica, ou quase maniqueísta, o sexo recebe atenção especial na produção dessas imagens, pois se, por um lado, é necessário cumprir o mandato divino que diz "crescei e multiplicaivos", por outro é, marcadamente, uma ocasião de pecado.Pela via do sexo e sob a ótica das autoridades eclesiásticas, as mulheres contêm 
em si a dicotomia: são, ao mesmo tempo, santas e pecadoras. E todas, até as que se dedicam à santidade e as que vivem na clausura, estão perseguidas pelo estigma do pecado. Por isso, todas são suspeitas.

Nesse aspecto as reflexões de Foucault podem contribuir para a compreensão desse procedimento:

Notaria apenas que, em nossos dias, as regiões onde a grade é mais cerrada, onde os buracos negros se multiplicam, são as regiões da sexualidade e as da política: como se o discurso, longe de ser esse elemento transparente ou neutro no qual a sexualidade se desarma e a política se pacifica, fosse um dos lugares onde elas exercem, de modo privilegiado, alguns de seus mais temíveis poderes. (....) o discurso (...) não é simplesmente aquilo que manifesta (ou oculta) o desejo; é, também, aquilo que é objeto do desejo; e visto que - isto a história não cessa de nos ensinar - o discurso não é simplesmente aquilo que traduz as lutas ou os sistemas de dominação, mas aquilo por que, pelo que se luta, o poder do qual nos queremos apoderar (Foucault, 1998: 9-10).

Outro aspecto fica evidente no documento: a mulher sozinha ou com seu marido não é objeto de consideração do episcopado. Sua condição social e cultural também não encontrou guarida no discurso dos prelados no início do século. Porém, quando a cena implicava na presença de sacerdotes e mulheres, além de provocar suspeitas, o discurso episcopal torna-se ordenativo, define comportamentos, dita normas e impõe restrições. Nesse aspecto, Bourdieu pode contribuir para a compreensão desse procedimento quando diz: “(...) os discursos não são apenas (a não ser excepcionalmente) signos destinados a serem compreendidos, decifrados; são também signos de riqueza a serem avaliados, apreciados e signos de autoridade a serem acreditados e obedecidos" (Bourdiev, 1996: 53).

Por se tratar de assunto extremamente delicado e complexo, os bispos não querem apenas ser compreendidos ou aceitos. Querem 
ser obedecidos, acreditados, respeitados, reconhecidos. Eles incorporam a definição da competência como direito à palavra, isso é, a linguagem legítima como linguagem autorizada, como linguagem de autoridade. Em outros termos, na qualidade de autoridades legitimamente instituídas, entendem que possuem o poder tanto de ordenar quanto de determinar a forma de recepção de sua determinação. Por isso, usam de sua autoridade para declarar uma verdadeira separação dos sexos. Seu discurso não tergiversa quando tratam de enquadrar como suspeitas todas as mulheres; das meninas no aprendizado do catecismo, às mulheres no interior do lar, na sacristia ou no confessionário, todas eram, em princípio, imaginadas e descritas como perigosas e, portanto, merecedoras de cuidados para não se constituírem em objeto de pecado.

Dessa forma, fica evidente que os prelados assumem sua condição de autoridade institucionalmente constituída, desempenhando a função de representantes da autoridade suprema, isto é, representantes de Deus na terra, convictos de que podem decretar a separação entre os sexos, definindo, doutrinariamente, a desigualdade entre homens e mulheres, mesmo que ambos tivessem sido criados à imagem do Deus, com a tarefa de dominar o mundo e prosseguir a obra da criação.

Embora tanto no Antigo quanto no Novo Testamento a presença da mulher esteja constantemente representada nas figuras de Maria, irmã de Moisés, das profetisas Débora, Hulda, Ruth, Judith, da Samaritana e das mulheres que acompanharam Cristo e o assistiram com seus bens, na imagem de coragem e dor demonstradas no episódio do calvário, na expressão de alegria e espanto daquelas que anunciaram aos apóstolos a ressurreição e, finalmente, no modelo "supremo" de mulher defendido pela Igreja - Maria, a mãe do Senhor a imagem construída pelos bispos não ultrapassou a esfera da mulher perigosa, fonte e objeto de pecado, suspeita e capaz de provocar e corromper as virtudes sacerdotais, levando-os a dar maus exemplos e a ter uma vida pouco recomendada.

Talvez os bispos temessem a repetição das cenas do período da Revolução Francesa, assim descritas por Michelle Perrot: 
Foi a primeira vez que indivíduos privados - em sua maioria mulheres e crianças - assumiram um papel público para defender a Igreja e seus ritos. Segundo o abade Grégoire, a Igreja constitucional foi estrangulada pelas "mulheres devassas e sediciosas"

Elas escondiam padres refratários, ajudavam a celebrar missas clandestinas e até missas brancas; depois do Termidor, instigavam maridos a irem exigir do governo a reabertura das igrejas; recusavam batizar ou casar os filhos com padres jurados; $e$, quando nada disso dava certo, realizavam manifestações em nome da liberdade religiosa. Em protesto contra a intromissão do Estado, voltou-se a cultuar santos padroeiros e, nas regiões mais hostis à Revolução, criaram-se novos mártires. A reza do rosário nas vigílias se transformou num ato de resistência política (РеRROT, 1995: 34).

Ficava estabelecido, pelo discurso da mais alta hierarquia da Igreja, que, na masculina ordem clerical, não havia espaço para a mulher, a não ser em condições muito específicas, previamente definidas pela autoridade institucional. Literalmente, no início do século $\mathrm{XX}$, os umbrais da Igreja eram propriedade dos homens e por eles rigidamente controlados.

Uma observação mais cuidadosa do texto das Constituições permi te perceber que a mulher aparece, no discurso católico, predominantemente como corpo. Um corpo sobre o qual se discursa muito mais em função de determinadas possibilidades do que de qualidades que ultrapassam os qualificativos físicos. Assim, a mulher é retratada como a possível mãe ou como alternativa pecaminosa. O processo de construção desse discurso é de tal ordem q-ue qualquer aproximação entre homens e mulheres, ou seja, entre padres e mulheres, padece de uma superação da visão de corpo. As situações descritas no texto insinuam que, no entender dos bispos, deveria ser comum a um dos sexos, quando se defrontasse com o outro, um convite para encontros amorosos ou pecaminosos. Para eles, ao que 
tudo indica, no cérebro das mulheres, as idéias ainda eram confundidas como depositárias de um corpo e não ao contrário.

Além disso, as Constituições revelam-se um proficuo instrumento de unificação discursiva com o objetivo de controlar o poder no interior do clero e entre os fiéis. Por isso, como objeto de poder, a produção de um discurso único e unificado visa a constituir mecanismos de controle. Tais mecanismos parecem bastante evidentes quando se observa que, na primeira metade do século XX, a Igreja católica se empenha na produção desses discursos traduzidos nas cartas pastorais do episcopado, tanto as coletivas, quanto as individuais, bem como no conjunto de documentos que registram os resultados de congressos católicos ou reuniões de associações de leigos e religiosos. Esse discurso único, assumido e ratificado por todo o episcopado e por lideranças leigas, induz a refletir sobre os mecanismos de poder instituidos no interior da Igreja, quer em relação aos fiéis, quer na luta contra outras instituições religiosas ou políticas. A unidade discursiva será fundamental para impor sua mensagem e garantir as condições para o controle social. Bourdieu ensina que, à medida que as representações mentais envolvem atos de apreciação e conhecimento, refletem estratégias de interesse e de manipulação. Nesse domínio, as coisas ditas, pensadas e expressas têm outro sentido além daquele manifesto. Nisto enquadra-se o controle das esferas do pensamento e das representações simbólicas, bem como a garantia da manutenção do monopólio sobre os bens sagrados.

Dessa forma a produção da imagem ou da representação da mulher contida na linguagem episcopal passa por um complexo sistema de filtros, por conflitos e divergências próprias dos discursos institucionais, nos quais enunciadores e enunciatários vivem realidades diversas, embora digam que obedecem aos mesmos princípios e aceitem as mesmas normas de comportamento. Por isso, na construção dessa imagem da mulher assumida e imposta pelos bispos, os fiéis pouco atuaram, prevalecendo os desejos, as concepções e as decisões dos hierarcas. Para os católicos do início do século XX a falta de informações e até mesmo de competência para definir procedimentos e normas de comportamento não lhes 
permitia entender o que acontecia, nem lhes cabia interferir nas esferas decisoŕias. Então, eram impelidos a obedecer, por força de uma construção discursiva ou pela ameaça da condenação e porque o discurso religioso veicula saber institucional e, portanto, exala poder. Nesse sentido, configura-se como discurso da verdade ou para a verdade e, por sua vez, esta se reveste do caráter de permanência em contraposição à obsolescência crescente do discurso leigo. Embora tenham transcorrido várias décadas, a leitura desse documento suscita interrogações sobre as relações que efetivamente se estabeleceram, ao longo dos séculos, no interior da Igreja, especialmente no que tange ao masculino e ao feminino, ao individual e ao coletivo. São situações complexas, mas que o documento coloca de forma direta e impositiva, considerando apenas a racionalidade que o momento demanda e que os interesses da instituição exigem.

Todavia, por ser um documento definidor da ordem institucional e das relações que devem prevalecer no interior de toda a instituição, observa-se a definição de padrões de comportamento, próprios de uma instituição que se organiza a partir de relações anônimas, funcionais e voltadas ao interesse da organização, em detrimento, muitas vezes, das necessidade do conjunto dos membros. Leonardo Bofif definiu com bastante clareza essa relação:

O fiel vai à Igreja; não precisa conhecer o celebrante
ou o confessor. Basta-lhe receber a eucaristia ou o
sacramento da penitência; a relação é anônima e cada
um desempenha sua função. A Igreja-sociedade se
apresenta estruturada de forma muito nítida: por um
lado o clero a quem cabe a gerência do sagrado e a
condução da vida eclesial e por outro a massa dos
fiéis, fregueses de paróquias e participantes de
movimentos que não afetam a estrutura hierárquica
(Boff, 1983:463).

Ocorre então, que na estrutura proposta pela Igreja e ratificada pelos bispos do Brasil em 1915, no texto das Constituições os homens 
controlam o sacerdócio, a administração dos sacramentos, os principais atos litúrgicos e a definição dos principios e normas de comportamento. A concepção masculina prevalece na linguagem do poder e no domínio e estruturação das funções ministeriais. No mundo ocidental, esta é uma concepção que se estruturou e consolidou ao longo dos séculos e, em que pesem os questionamentos dos renascentistas, os ataques do iluminismo, a "irreligiosidade" do século XIX e as mudanças do século das luzes, pouco se acrescentou de essencial na constituição da hierarquia da Igreja. As mulheres continuaram excluídas da direção e da cúpula da instituição e, com freqüência, embora descritas e concebidas como assexuadas, eram consideradas como elemento de risco e pecado.

Fica evidenciado que o discurso institucional católico constituise numa narrativa que é construida e enriquecida pelas opções dos sujeitos da enunciação e de suas relações com as idéias que enunciam. Neste caso específico, os enunciadores (bispos) estão imbuídos das condições e dos mecanismos institucionais para fazê-lo. São sujeitos que ocupam os mais altos cargos na hierarquia de poder e como tal são aceitos pelos membros da instituição.

Vale lembrar que a eficácia simbólica do discurso religioso reside muito mais na apreensão da institucionalidade consagrada dos atos de enunciação do que propriamente no conceito que eles propõem. A legitimidade e autoridade do discurso é proporcional ao capital simbólico construido e reconstruido em diversos contextos históricos. Por isso, naquele momento e naquele contexto, os bispos personificam o poder de enunciar e agir em nome da Igreja. Eles são a Igreja ou parte significativa dela, instituídos para o exercício do poder e da elaboração do discurso. Há, por assim dizer, um poder fora da palavra que rege o argumento e que faz valer a eficácia do discurso. Dessa forma, o rito da linguagem está intimamente ligado à posição social da autoridade investida, sendo ela ator da performance pela qual a própria instituição é reconhecida.

Os sujeitos da enunciação são autoridades institucionalmente constituídas e certamente possuem clareza do perfil dos destinatários e, por isso, articulam suas figurações discursivas às pessoas, aos 
lugares e às instituições que os fiéis identificam e reconhecem como entidades reais e visíveis. A representação produzida assume, assim, um sentido de realidade. Além disso, esse discurso institucional define o relacionamento entre os padres e as mulheres como algo não mais pertencente ao universo do privado. Esse relacionamento somente será aceito e avalizado se ocorrer exclusivamente no espaço público. Em conseqüência, o privado é visto como a zona do maldito, do suspeito. Local proibido para esses relacionamentos porque nele circulam a tentação e as oportunidades de pecado e de maldizer.

A lógica desse discurso tomar-se-á irrefutável se os especialistas da religião conseguirem mantê-la imutável e produzirem representações que o tornem verdadeiro para os fiéis. A mística do poder completar-se-á quando forem capazes de conjugar ao discurso verbal o texto não verbal expresso em figuras e rituais.

Um dos rituais mais marcados pela representação simbólica e que mereceu a atenção dos bispos foi o sacramento da confissão. Trata-se aqui da confissão auricular cuja ritualística pressupõe a aproximação entre confessante e confessor, num contexto de profunda intimidade e de domínio das consciências. A Igreja empenhou-se em levar o pecador a confessar seus pecados para que, ao receber do padre o perdão divino, pudesse sentir-se confortado em relação às suas fraquezas humanas. Ao acreditar no poder de perdoar e na eficácia do ritual, impôs aos seus fiéis a obrigatoriedade de confessar os pecados, de forma privada e auricular, ao menos uma vez por ano. Assim normatizada, a confissão tomava-se poderoso instrumento de poder nas mãos do clero, uma vez que, ao ser desobedecida, poderia decretar a definitiva condenação ao inferno

Como entender o discurso episcopal, ao colocar tantas suspeitas sobre a realização de um ritual tornado obrigatório? Não estariam contribuindo para confirmar a oposição a ela sustentada no decorrer do século XIX? Jean Delumeau destaca que:

No século XIX se afirmará abertamente uma

hostilidade virulenta - sobretudo masculina - com

relação à confissão. Ela será acusada de intervir na

Significação $14 \cdot 254$ 
intimidade dos lares, de opor a mulher ao homem, a religião à política, a escola confessional à leiga, a nostalgia do Antigo Regime ao progresso republicano.

Será denunciada como um abuso de poder. Seus adversários perderão de vista seus objetivos maiores: confortar e perdoar (Delumeau, 1991: 131).

É evidente que nenhuma dessas críticas era aceita pelo episcopado; todavia, ao levantar tantas suspeitas e ao normatizar de forma tão detalhada os procedimentos rituais na relação de confissão das mulheres, quer fossem leigas, quer fossem freiras, o próprio discurso episcopal colocava entraves ao valor simbólico do ritual. Se induz à situação de pecado, por que torná-la obrigatória?

Aqui está expresso o duplo mecanismo de controle: por um lado, o controle sobre os sacerdotes no seu relacionamento com as mulheres e, por outro, talvez mais importante, o controle sobre um dos principais bens de salvação - o perdão dos pecados e reconciliação com Deus. O monopólio sobre o poder de salvar compensava os riscos e as críticas dos adversários. Garantida a lisura do ritual, estava dado um dos mais significativos mecanismos de controle das consciências e de possibilidade de manipulação discursiva.

Finalmente, partindo do pressuposto de que nenhum discurso é neutro, muito menos o discurso episcopal, pode-se dizer que as Constituições, mesmo vistas apenas sob um aspecto, são formas de produzir mensagens, estratégias e práticas que atendem aos objetivos de manter o controle não apenas sobre as mulheres, mas especialmente sobre o clero, cujo comportamento celibatário ou o cumprimento do voto de castidade nem sempre eram prioritários.

Segundo Altusser a ideologia religiosa tende sempre a transformar os indivíduos em sujeitos submissos à condição de escolha passiva em relação ao sujeito principal ao qual todo o enunciado se refere. Assim, caracteriza o discurso religioso como aquele em que fala a voz de Deus e qualquer representante seu é a voz da divindade.

No âmbito do discurso religioso é preciso identificar se o enunciador está devidamente consagrado em relação ao discurso feito 
e sacralizado em texto que se reporta ao plano da divindade e ainda se esse discurso refere-se ao enunciador devidamente consagrado institucionalmente, portanto, autorizado em relação aos enunciatários no plano temporal.

Essa talvez seja uma das razões por que a Igreja sempre foi bastante cuidadosa na constituição de um corpo de especialistas da religião que tem como objetivo garantir o monopólio tanto da produção de discursos, quanto da gestão dos bens de salvação e das diretrizes teológicas, controlando, dessa forma, os sistemas simbólicos (discursivos, rituais e pictóricos) e as ideologias religiosas (teogonias e monogonias). Enquanto isso, a maioria dos crentes, qualificada como "leigos", continua destituída de força produtora de bens simbólicos, relegada à condição de espectadora da vida da Igreja.

Finalmente, a capacidade de produção de sistemas simbólicos e manutenção desse monopólio implica a necessidade de incorporar ou suprimir qualquer produção discursiva que coloque em dúvida tanto o controle, quanto a distribuição desses bens. Isto explica as reações contra aqueles que tentam elaborar outras mensagens discursivas como, por exemplo, os profetas, feiticeiros, bruxos, conselheiros, ou outras figuras do folclore ou da fé popular. Sua atuação coloca em risco a unidade discursiva e a centralização do poder. Por isso, as possíveis ameaças a essa unidade eram duramente combatidas e seus autores ou eram cooptados ou excluídos do conjunto dos seus especialistas da religião.

\section{Bibliografia}

BOFF, Leonardo. CEBs. A Igreja inteira na base. Revista eclesiástica brasileira. Vol. 43, fase. 171. Petrópolis: Vozes, 1983.

BOURD1EU, Pierre. A economia da trocas simbólicas. São Paulo: Perspectiva, 1992.

. A economia das trocas lingüísticas. São Paulo: Edusp, 1996.

CERTEAU, Michel de. A escrita da história. Rio de Janeiro: ForenseUniversitária, 1982.

Significação $14 \cdot 256$ 
DELUMEAU, Jean. A confissão e o perdão. São Paulo: Companhia das Letras, 1991.

FOUCAULT, Michel. A ordem do discurso. 4a ed. São Paulo: Loyola, 1998.

IGREJA CATÓLICA. BISPOS. Constituições das Províncias Eclesiásticas Meridionaes do Brasil. Rio de Janeiro: Typ. Martins de Araújo \& C., 1915.

BISPOS. Acta et Decreta Concilii Plenarii AMERICAE

LATINAE. Romae: Typis aticanis, MCMII.

ORLANDI, Eni P. A linguagem e seu funcionamento. As formas do discurso. São Paulo: Brasiliense, 1983.

. (org.). Palavra, fé epoder. Campinas, São Paulo: Pontes, 1987

PERROT, Michelle.Práticas da memória feminina. Revista brasileira de história. A mulher e o espaço público. Vol. 9, $\mathrm{n}^{\circ}$ 18. São Paulo: Marco-Zero/Anpuh, 1989.

. Em que ponto está a história das mulheres na Europa. Revista brasileira de história. Vol. 14, $\mathrm{n}^{\circ}$ 28. São Paulo: Anpuh/MarcoZero, 1994.

-(org.). História da vida privada. Da Revolução Francesa à Primeira Guerra. São Paulo: Companhia das Letras, 1995. 